\title{
BORROWING FROM EMPLOYEES: \\ WAGE DYNAMICS WITH FINANCIAL CONSTRAINTS
}

Claudio Michelacci and Vincenzo Quadrini

CEMFI Working Paper No. 0501

January 2005

CEMFI

Casado del Alisal 5; 28014 Madrid

Tel. (34) 914290 551. Fax (34) 914291056

Internet: www.cemfi.es 
CEMFI Working Paper 0501

January 2005

\title{
BORROWING FROM EMPLOYEES: WAGE DYNAMICS WITH FINANCIAL CONSTRAINTS
}

\begin{abstract}
We analyze how the financial conditions of the firm affect the compensation structure of workers, the size of the firm, and its dynamics. Firms that are financially constrained offer long-term wage contracts characterized by an increasing wage profile, that is, they pay lower wages today in exchange of higher future wages, effectively borrowing form their employees. Because constrained firms also operate at a suboptimal scale, which then increases gradually over time, we have that younger and smaller firms grow faster and pay lower wages.
\end{abstract}

JEL Codes: G31, J31, E24.

Keywords: Investment financing, long-term contracts, wages.

Claudio Michelacci

CEMFI

c.michelacci@cemfi.es
Vicenzo Quadrini

University of Southern California

quadrini@usc.edu 


\section{Introduction}

The empirical evidence suggests that firms differ in the wages they pay. Brown and Medoff (1989) document a positive association between wages and the size of the employer. Krueger and Summers (1988) find persistent differences in wages across industries. Abowd and Kramarz (2000) document that employers' characteristics account for a relevant part of the dispersion of wages. These findings are often regarded as suggesting the existence of some form of labor market imperfections. In this paper we show that financial market imperfections can also contribute to generate a dependence of wages from the characteristics of the employers.

Our interest in understanding the impact of financial factors on wages is motivated by a set of regularities relating the financial conditions of the firm to its size, dynamics and the wages it pays. As discussed in Cooley and Quadrini (2001), the view that emerges from the financial literature is that small and fast growing firms face tighter financial constraints, either in the form of lower ability to raise funds or in the form of higher cost of funds. It also appears that financially distressed firms pay lower wages. See Nickell and Nicolitsas (1999), Hanka (1998) and Blanchflower, Oswald, and Garrett (1990).

We study a model in which workers are ex-ante identical and the labor market is perfectly competitive. However, firms may face different financial conditions along the life-cycle. If the investment that the firm can finance with external investors is limited - that is, the firm is financially constrained - it will find optimal to sign long-term contracts with their employees, offering wage profiles that are increasing with the tenure of the 
worker. By paying lower wages today in exchange of higher future wages, the firm implicitly borrows from its employees. Overtime, the reinvestment of profits relaxes the financial constraints and the firm grows in size. Thus, the model predicts that wages increase with the age and size of the firm. At the same time, because constrained firms grow in size, we also have that growing firms pay lower wages.

The ability of the firm to borrow from workers beyond what it can borrow from external investors is made possible by a form of implicit "collateral" available only to workers. In the event of repudiation, external investors can punish the firm only by confiscating its physical assets, which represent the only collateral that the firm can use to raise funds in financial markets. Workers, instead, can also punish the firm by withdrawing their effort and quitting. If the replacement of workers is costly - due to recruiting costs, training expenses and the loss of job specific human capital — workers have a credible punishment tool in the event of repudiation that is not available to investors. This can be used to sustain the long-term wage contracts between the firm and its workers.

There is both direct and indirect evidence that firms do borrow from their employees. In some cases, firms borrow explicitly from their workers. ${ }^{1}$

\footnotetext{
${ }^{1}$ An example is Energy Services Group International, an energy-services engineering and construction company in Williamsburg, VA. The company got a major new contract from an electric utility in Florida but it could not persuade banks to lend any more money. Only employees came forward with investments that ranged from $\$ 200$ to $\$ 74,000$ in exchange of promissory notes. See Inc. Magazine, January 1992, http://www.inc.com/magazine/19920101/3886.html.
} 
In others, the borrowing is implicit in the compensation structure offered to employees, as in our model. For example, the widespread use of stock options and/or stock grants to ordinary workers - whose effort, when individually considered, is likely to have a negligible effect on the overall value of the firm - can hardly be justified as a way to provide better incentives to workers. This view is also expressed in Hall and Murphy (2003). Most likely, with the use of stock options, firms delay the cash compensation of their employees and effectively borrow from them. In accordance with this interpretation, Core and Guay (2001) provide direct evidence that the use of stock options is more common among financially constrained firms.

The plan of the paper is as follows. The next section describes the model and Section 3 characterizes the wage policy and dynamics of the firm. Section 4 discusses the implementation of the long-term wage contract and Section 5 outlines possible extensions for future research.

\section{The model}

Consider a risk-neutral entrepreneur with initial wealth $a_{0}$ and with lifetime utility $\sum_{t=0}^{\infty} \beta^{t} c_{t}$, where $\beta$ is the intertemporal discount factor and $c_{t}$ is consumption.

The entrepreneur has the managerial skills to run an investment project that generates revenues $y=A \cdot N$. The variable $N$ denotes the number of hired workers and $A$ is a constant. The project is subject to the capacity constraint $N \leq \bar{N}$.

The employment of each worker requires two types of fixed investment: fungible investment, $\kappa_{f}$, and worker-specific investment, $\kappa_{w}$. The first type 
of investment, $\kappa_{f}$, has an external value and can be resold at no cost. The second type, $\kappa_{w}$, represents the cost incurred by the firm in recruiting and training a new worker for the specific job. The worker-specific investment is lost if the worker quits or is fired. As we will discuss later, this second component of the investment plays a central role for the non-renegotiation of the wage contract. Let $\kappa \equiv \kappa_{f}+\kappa_{w}$ denote the total per-worker investment. Then the total capital accumulated at the end of time $t$ by a firm created at time zero is $\kappa \sum_{\tau=0}^{t} n_{\tau}$, where $n_{\tau}$ is the number of workers hired at time $\tau$ (and start producing at time $\tau+1$ ). The output produced by the firm at $t+1$ is $A \sum_{\tau=0}^{t} n_{\tau}$.

The investment $\kappa$ necessary to employ a worker creates a financial need for the firm. Part of the funds are raised from financial markets where there is a continuum of atomistic investors supplying funds at the fixed rate $r$. Using the renegotiation idea of Hart and Moore (1994) and Kiyotaki and Moore (1997), the entrepreneur can borrow only the amount that can be collateralized. In case of liquidation, investors can seize only the fungible capital $\kappa_{f}$. Since the collateral must also guarantee the interests on the loan, the firm can borrow at most $\bar{\kappa}_{f}=\kappa_{f} /(1+r)$ per each worker. The borrowing limit, then, can be written as $b_{t} \leq \bar{\kappa}_{f} \sum_{\tau=0}^{t} n_{\tau}$, where $b_{t}$ denotes the debt level contracted at time $t$. We assume that $1 /(1+r) \geq \beta$. This guarantees that external financing is never dominated by internal financing.

Workers are infinitely lived with lifetime utility $\sum_{t=0}^{\infty} \beta^{t} U\left(c_{t}\right)$, where $\beta$ is the discount factor, and the function $U\left(c_{t}\right)$ is strictly increasing and strictly concave. For simplicity we assume that workers cannot save and/or borrow. Therefore, consumption is simply equal to their wages. 
When new workers are hired, the firm signs long-term contracts that specify the whole sequence of wages paid to each individual worker. Because the labor market is competitive, the initial lifetime utility is equal to the market-clearing level offered to all newly hired workers. This value, which is exogenous in the model, is also the reservation value for the worker, that is, the value that the worker would earn by re-entering the labor market. We denote the reservation value by $q_{\text {res }}$.

\section{The firm's problem and dynamic properties}

We start characterizing the optimization problem under the assumption that the firm and the workers commit not to renegotiate the long-term wage contracts. After characterizing the optimal solution with commitment, we will discuss in the next section the conditions under which the long-term contracts are free from renegotiation.

Let $\left\{w_{t, t+j}\right\}_{j=1}^{\infty}$ be the sequence of wages that the firm promises to the workers hired at time $t$. Here $w_{t, t+j}$ denotes the wage paid at time $t+j$ to workers hired at time $t$. The total wage payments at time $t+1$ are $\sum_{\tau=0}^{t} n_{\tau} w_{\tau, t+1}$. Let $a_{t}$ denote the net worth of the firm at the end of period $t$ - that is, after production and after the payment of wages and interests. The firm's net worth, $a_{t}$, plus the debt, $b_{t}$, is equal to the sum of the firm's capital, $\kappa \sum_{\tau=0}^{t} n_{\tau}$, and the dividends, $d_{t}$. Thus, $d_{t}=a_{t}+b_{t}-\kappa \sum_{\tau=0}^{t} n_{\tau}$.

Given the initial assets $a_{0}$, the firm maximizes the discounted value of the entrepreneur's consumption. Consumption is equal to the dividends since the entrepreneur is at least as impatient as the market, that is, $\beta \leq 1 /(1+r)$. Thus, at time zero, the firm chooses the whole sequence of debt, employment 
and wages to solve the problem:

$$
\begin{aligned}
V\left(a_{0}\right)= & \max \\
\left\{b_{t}, n_{t},\left\{w_{t, t+j}\right\}_{j=1}^{\infty}\right\}_{t=0}^{\infty} & \sum_{t=0}^{\infty} \beta^{t} d_{t} \\
& \text { subject to } \\
& d_{t}=a_{t}+b_{t}-\kappa \sum_{\tau=0}^{t} n_{\tau} \geq 0, \\
& b_{t} \leq \bar{\kappa}_{f} \sum_{\tau=0}^{t} n_{\tau}, \\
& \sum_{j=1}^{\infty} \beta^{j} U\left(w_{t, t+j}\right) \geq q_{r e s}, \\
& a_{t+1}=(\kappa+A) \sum_{\tau=0}^{t} n_{\tau}-\sum_{\tau=0}^{t} n_{\tau} w_{\tau, t+1}-(1+r) b_{t},
\end{aligned}
$$

with $a_{0}$ given. Equation (2) defines the dividends, that are constrained to be non-negative because consumption cannot be negative. Constraint (3) imposes the borrowing limit and (4) is the worker's participation constraint. This imposes that the lifetime utility generated with the sequence of wages offered to a new hired worker, cannot be smaller than its reservation value $q_{\text {res }}$. In general this constraint should be imposed not only when the worker is hired but at any future date. However, as we will see later, the lifetime utility never falls below $q_{\text {res }}$. Finally, constraint (5) defines the law of motion for the end-of-period net worth.

Let $\gamma_{t}, \mu_{t}$ and $\lambda_{t} n_{t}$ be the lagrange multipliers associated with constraints (2), (3) and (4), respectively. The first order conditions with respect to $b_{t}$ (debt contracted in period $t$ ) and $w_{\tau, t}$ (wage paid at time $t$ to workers hired at time $\tau$ ) are:

$$
\mu_{t}=1+\gamma_{t}-\beta(1+r)\left(1+\gamma_{t+1}\right)
$$




$$
\lambda_{\tau} U_{c}\left(w_{\tau, t}\right)=1+\gamma_{t}
$$

The variable $\mu_{t}$ is the value of an additional unit of debt by relaxing the borrowing limit, and $1+\gamma_{t}$ is the value of an additional unit of internal funds. If the non-negativity constraint on dividends is binding, $\gamma_{t}$ is positive. Therefore, one additional unit of internal funds has a value greater than 1 .

Condition (6) says that the value of one additional unit of debt, $\mu_{t}$, is equal to the firm's valuation of the cash flows generated by this additional debt. By borrowing more, the firm gets immediately one unit of funds or cash flow. This has a value of $1+\gamma_{t}$. In the next period, however, the firm has to repay $1+r$, which will be valued at $1+\gamma_{t+1}$. Therefore, the current value of the debt repayment is $\beta(1+r)\left(1+\gamma_{t+1}\right)$.

To interpret (7), notice that the variable $\lambda_{\tau}$ is the marginal cost to the firm of providing one unit of utility to a worker hired at time $\tau$, while $U_{c}$ denotes the marginal utility of consumption. This implies that the term $\lambda_{\tau} U_{c}\left(w_{\tau, t}\right)$ is the marginal cost of reducing wages. Therefore, condition (7) says that the optimal wage policy of the firm is such that the marginal cost of reducing wages at time $t$ (and increasing the current cash flows) is equal to the marginal value of internal funds. In other words, the firm borrows from a worker until the cost of this type of borrowing is equal to the marginal value of internal funds.

\subsection{Firm and wage dynamics}

Equations (6) and (7) allow us to characterize some basic properties of the dynamics and wage structure of the firm. Let's observe first that, if the initial wealth of the entrepreneur $a_{0}$ is small, the firm is initially unable to 
finance the investment necessary to employ the optimal number of employees $\bar{N}$. Since the firm is financially constrained, we have that the non-negativity constraint on dividends (2) and the borrowing limit (3) are both binding, and therefore, $\mu_{t}>0$ and $\gamma_{t}>0$. Equation (6) then implies that $\gamma_{t}$ declines over time until it approaches zero. ${ }^{2}$ As the firm retains its earnings and accumulates internal wealth, the firm hires more workers and eventually it reaches the optimal scale $\bar{N}$. Thus, we have the following property:

P1: Financially constrained firms are younger, smaller and grow faster.

This property is common to other models with financial market frictions. ${ }^{3}$ The novelty of the paper to show how financial market frictions affect the wage policy of the firm and how this policy relates to the dynamics of the firm. To analyze this issue, consider equation (7). The multiplier $\gamma_{t}$ captures the tightness of financial constraints and depends on the firm's net worth. If $a_{t}$ is small, the financial needs of the firm are high, which implies that the value of an extra unit of internal funds is also high. As the firm retains earnings, its assets increase over time and the variable $\gamma_{t}$ decreases monotonically to zero. Equation (7) then shows that the wages paid to each cohort of

\footnotetext{
${ }^{2}$ This property can be clearly seen in the special case in which $\beta(1+r)=1$. In this case equation (6) reads as $\mu_{t}=\gamma_{t}-\gamma_{t+1}$, which says that $\gamma_{t}$ decreases over time when $\mu_{t}$ is strictly positive. Although the decreasing pattern of $\gamma_{t}$ can be seen clearly only in this special case, this property also holds when $\beta(1+r)<1$.

${ }^{3}$ See, for example, Albuquerque and Hopenhayn (2004), Cooley and Quadrini (2001), Cooley, Marimon, and Quadrini (2004), Clementi and Hopenhayn (1998) and Quadrini (2004).
} 
workers increase over time until $\gamma_{t}=0$. At this point the firm is financially unconstrained. ${ }^{4}$ We summarize this property as follows:

P2: The wages paid to each cohort of workers increase over time until the firm becomes unconstrained.

Another important property is that, within the same firm, workers with longer employer tenure receive higher wages than more recent hires. To show this, consider again condition (7). As observed above, the declining value of $\gamma_{t}$ implies that wages increase over time. This also implies that the lifetime utility of workers increases. Because all workers start with the same utility level, $q_{r e s}$, new hires have an initial utility that is smaller than older workers. But then, since condition (7) also implies that the ratio of marginal utilities for any two cohorts of workers remains constant, we must have that new hires receive lower wages than older workers at any point in time. In summary:

P3: Within the same firm, senior workers earn higher wages than junior workers.

Figure 1 shows the above properties with a numerical example in which the utility function takes the $\log$-form $U\left(c_{t}\right)=\log \left(c_{t}\right)$, and the parameters values are as follows: $r=0.03, \beta=0.934, q_{\text {res }}=U(0.6) /(1-\beta), A=1$, $\bar{N}=1,000, \kappa=2.8, \kappa_{f} / \kappa=0.3$, and $a_{0}$ is such that the initial size of the firm is 10 percent the maximum scale. This is obtained by setting $a_{0}=196$.

\footnotetext{
${ }^{4}$ Notice that, if $\beta(1+r)<1$, the borrowing limit is still binding when $\gamma_{t}=0$. Yet the firm is financially unconstrained in the sense that the firm could increases its debt capacity by retaining its earnings.
} 
Figure 1: Employment dynamics and wage patterns over age and size.
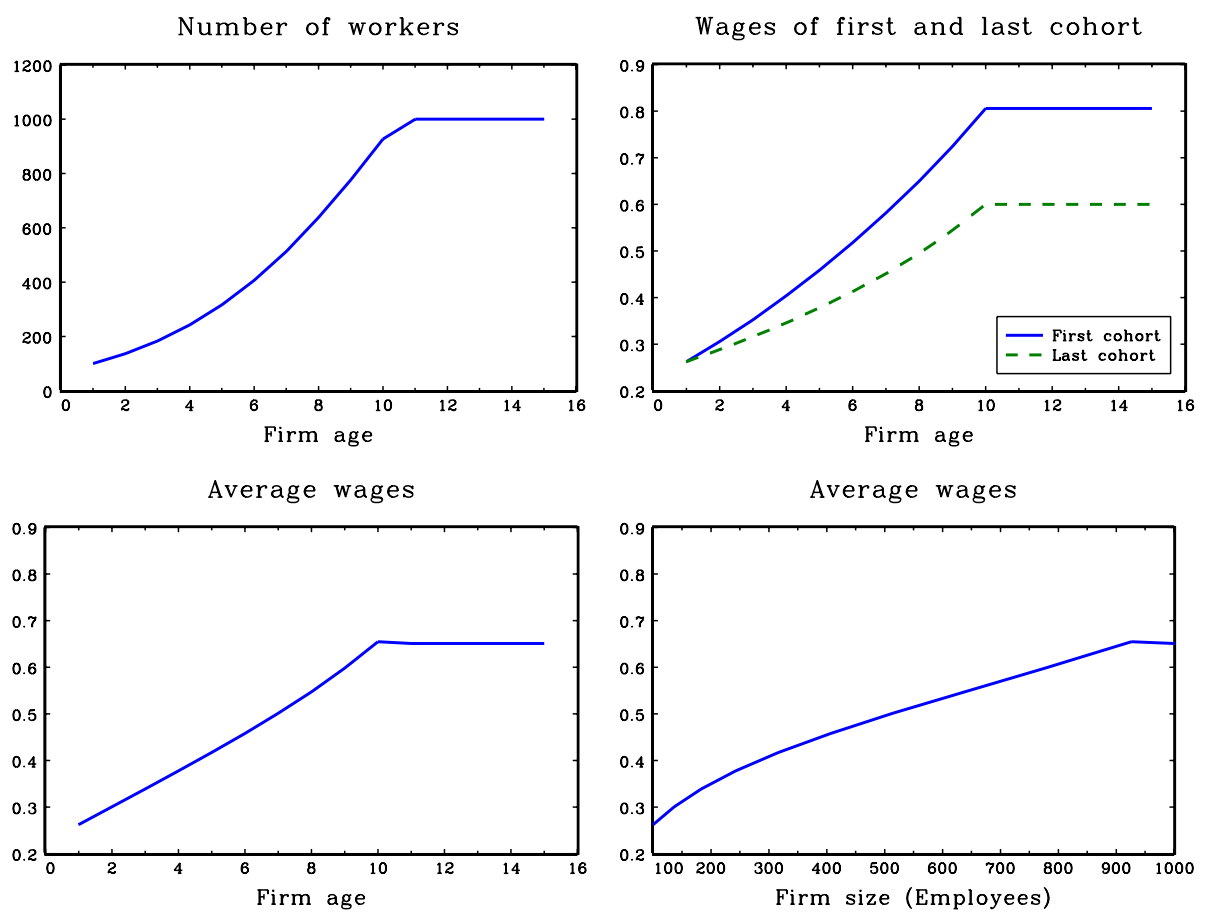

The first panel of Figure 1 plots the employment dynamics. The firm starts with an initial employment of 100 workers and then gradually grows over time until it reaches the optimal scale $\bar{N}=1,000$. The transition takes place in 11 periods. The second panel plots the wage profile of the first cohort of workers (those hired at time 0 ) and the initial wage paid to newly hired workers. The wage profile of the first cohort of workers (continuous line) is increasing until the firm reaches the unconstrained status. The dashed line is the wage earned by the newly hired cohort of workers. As the firm gets closer to the optimal scale, it offers higher initial wages, and therefore, the wage profile of more recent workers is less steep overall. 
The third panel plots the average wage paid by the firm as a function of its age and the fourth panel the average wage as a function of its size (measured by the number of employees). The average wage increases with the size and age of the firm. This is a direct consequence of the fact that, when the firm is young and constrained, it operates at a suboptimal scale and offers an increasing profile of wages.

Especially important for the overall dynamics of wages is the concavity of the workers' utility $U\left(c_{t}\right)$ and the initial assets $a_{0}$. To analyze the effects of differences in the degree of concavity, assume that the utility function takes the form $U\left(c_{t}\right)=\left(c_{t}^{1-\sigma}-1\right) /(1-\sigma)$. As shown in the first panel of Figure 2, the lower is the concavity and the stronger is the size dependence of wages. Clearly, with a smaller $\sigma$ the worker is more willing to accept a nonflat consumption profile and it becomes cheaper for the firm to borrow from workers. In the extreme case in which $\sigma=0$ (linear utility), the financing premium required by the workers is zero. In this case the firm would pay zero wages until it can operate at the optimal scale.

The initial assets of the firm also play an important role. For given $\bar{N}$, smaller values of $a_{0}$ imply tighter financial constraints, that is, the firm is constrained to start with a smaller scale. This also implies that the firm has a greater incentive to rely on its wage policy to finance its growth. As a result, it pays smaller initial wages as shown in the second panel of Figure 2.

We summarize the above properties as follows:

P4: The initial wages are lower when the firm faces tighter constraints (smaller initial assets) and the worker utility is less concave (cheaper cost of borrowing). 
Figure 2: Wage dynamics for different utility curvatures and initial assets.
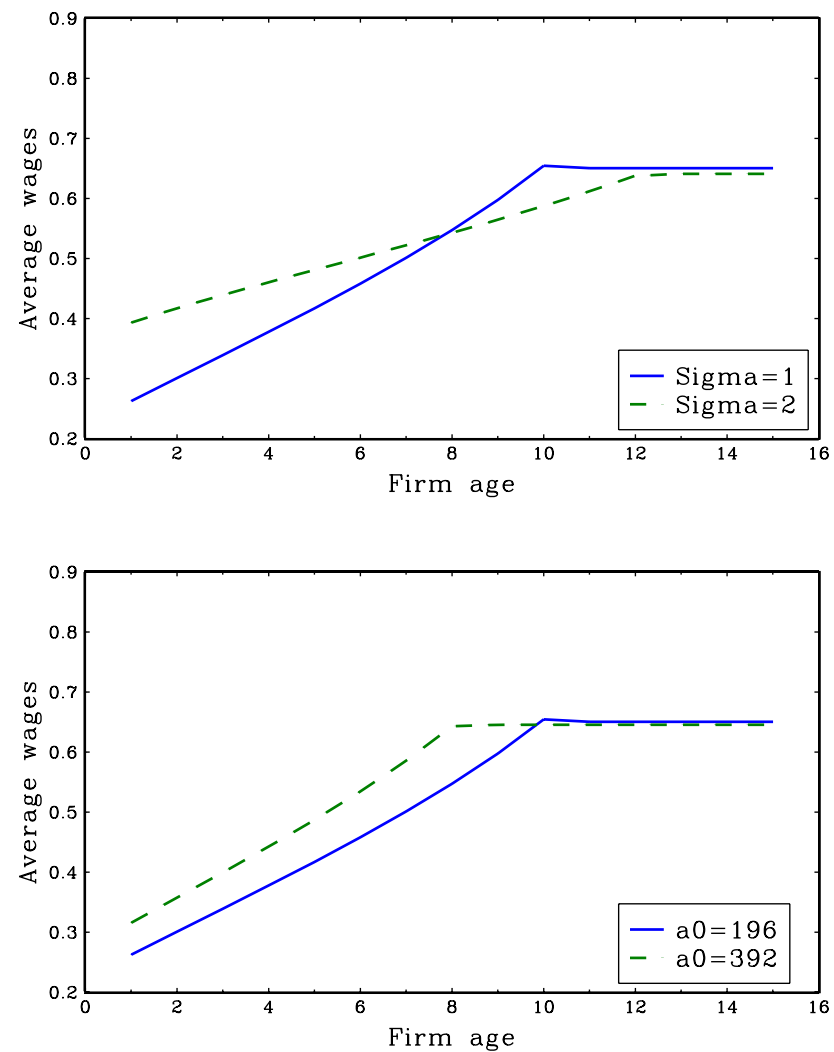

\section{Contract enforceability}

The analysis conducted in the previous section was based on the assumption that firms and workers commit to the long-term wage contract. In this section we consider the conditions under which this contract is free from renegotiation. For limitation of space we only provide an intuitive discussion. For the detailed analysis see Michelacci and Quadrini (2004).

As we have seen in the previous section, the wage profile is increasing or 
constant. This implies that the worker's lifetime utility is always greater or equal to the reservation utility $q_{\text {res }}$. Therefore, the worker will never renege the contract.

The renegotiation problem for the firm is more complex. The increasing profile of wages implies that the firm does have an incentive to renege. In fact, the firm could always replace an existing worker with a new hire, to whom it would offer a contract with initial lifetime utility $q_{r e s}$. Because this initial utility is smaller than the utility promised to an existing worker, the firm would gain by replacing the worker. To prevent this possibility, workers must have some direct or indirect mechanism to punish the firm in case it reneges the contract. This mechanism is provided by the worker-specific investment $\kappa_{w}$ which is lost if the worker quits the firm. It can be shown that, if $\kappa_{w}$ is sufficiently large, the optimal contract can be sustained by trigger strategies in which the worker provides effort as long as the firm pays the contracted wages, while he or she will quit if the firm reneges its promises. In a way, the worker-specific investment acts as a collateral for the worker's credit toward the firm, which is not available to external investors.

Of course, there is a limit to the amount of credit that the firm can get from workers. In particular, if the initial wealth $a_{0}$ is small and the worker's utility is not very concave, then the profile of wages is very steep. This implies that at some point the firm will have an incentive to renege. In this case the firm has to rely on some other implementation mechanism to borrow from workers. The grants of assets, such as stock options, may serve this purpose. 


\section{Conclusion}

In this paper we have studied how the financial condition of the firm affects its wage policy. In the (static) perfectly competitive labor market model, wage differences just reflect differences in workers' abilities. In reality, firms' characteristics account for a relevant part of the observed dispersion in earnings. This is usually taken as evidence of labor market imperfections. In our model workers are (ex-ante) identical and the labor market is perfectly competitive. Yet, due to financial market imperfections, workers' earnings also depend on the characteristics of their employers. In particular, wages tend to increase with the age and size of the firm. This may be important in explaining the robust empirical finding that larger firms pay higher wages (see Brown and Medoff (1989) and Oi and Idson (1999)). In Michelacci and Quadrini (2004) we investigate this possibility by using a more general theoretical framework. 


\section{References}

Abowd, J. M. and F. Kramarz (2000). Inter-industry and firm-size wage differentials: New evidence from linked employer-employee data. Unpublished manuscript, Cornell University.

Albuquerque, R. and H. Hopenhayn (2004). Optimal lending contracts and firms dynamics. Review of Economic Studies 71(2), 285-315.

Blanchflower, D., A. Oswald, and M. Garrett (1990). Insider power in wage determination. Economica 57(226), 143-70.

Brown, C. and J. Medoff (1989). The employer size-wage effect. Journal of Political Economy 97(5), 1027-59.

Clementi, G. and H. A. Hopenhayn (1998). Optimal lending contracts and firms' survival with moral hazard. Unpublished manuscript, Carnegie Mellon University and University of Rochester.

Cooley, T. F., R. Marimon, and V. Quadrini (2004). Aggregate consequences of limited contracts enforceability. Journal of Political Economy 111(4), 421-46.

Cooley, T. F. and V. Quadrini (2001). Financial markets and firm dynamics. American Economic Review 91(5), 1286-1310.

Core, J. and W. Guay (2001). Stock option plans for non-executive employees. Journal of Financial Economics 61, 253-287.

Hall, B. and K. Murphy (2003). The trouble with stock options. Journal of Economic Perspectives 17(3), 49-70. 
Hanka, G. (1998). Debt and the terms of employment. Journal of Financial Economics 48(3), 245-82.

Hart, O. and J. Moore (1994). A theory of debt based on the inalienability of human capital. Quarterly Journal of Economics 109, 841-79.

Kiyotaki, N. and J. H. Moore (1997). Credit cycles. Journal of Political Economy 105(2), 211-48.

Krueger, A. and L. Summers (1988). Efficiency wages and the interindustry wage structure. Econometrica 56, 259-294.

Michelacci, C. and V. Quadrini (2004). Financial markets and wages. Unpublished manuscript, CEMFI and University of Southern California.

Nickell, S. and D. Nicolitsas (1999). How does financial pressure affect firms? European Economic Review 43(8), 1435-56.

Oi, W. and T. Idson (1999). Firm size and wages. In O. Ashenfelter and D. Card (Eds.), Handbook of Labour Economics, pp. Volume 3B. Amsterdam: North Holland.

Quadrini, V. (2004). Investment and liquidation in renegotiation-proof contracts with moral hazard. Journal of Monetary Economics 51(4), $713-751$. 


\section{CEMFI WORKING PAPERS}

0301 Rubén Hernández-Murillo and Gerard Llobet: "Patent licensing revisited: Heterogeneous firms and product differentiation".

0302 Cristina Barceló: "Housing tenure and labour mobility: A comparison across European countries".

0303 Víctor López Pérez: "Wage indexation and inflation persistence".

0304 Jesús M. Carro: "Estimating dynamic panel data discrete choice models with fixed effects".

0305 Josep Pijoan-Mas: "Pricing risk in economies with heterogenous agents and incomplete markets".

0306 Gabriele Fiorentini, Enrique Sentana and Giorgio Calzolari: "On the validity of the Jarque-Bera normality test in conditionally heteroskedastic dynamic regression models".

0307 Samuel Bentolila and Juan F. Jimeno: "Spanish unemployment: The end of the wild ride?".

0308 Rafael Repullo and Javier Suarez: "Loan pricing under Basel capital requirements".

0309 Matt Klaeffling and Victor Lopez Perez: "Inflation targets and the liquidity trap".

0310 Manuel Arellano: "Modelling optimal instrumental variables for dynamic panel data models".

0311 Josep Pijoan-Mas: "Precautionary savings or working longer hours?".

0312 Meritxell Albertí, Ángel León and Gerard Llobet: "Evaluation of a taxi sector reform: A real options approach".

0401 Andres Almazan, Javier Suarez and Sheridan Titman: "Stakeholders, transparency and capital structure".

0402 Antonio Diez de los Rios: "Exchange rate regimes, globalisation and the cost of capital in emerging markets".

0403 Juan J. Dolado and Vanessa Llorens: "Gender wage gaps by education in Spain: Glass floors vs. glass ceilings".

0404 Sascha O. Becker, Samuel Bentolila, Ana Fernandes and Andrea Ichino: "Job insecurity and children's emancipation".

0405 Claudio Michelacci and David Lopez-Salido: "Technology shocks and job flows".

0406 Samuel Bentolila, Claudio Michelacci and Javier Suarez: "Social contacts and occupational choice".

0407 David A. Marshall and Edward Simpson Prescott: "State-contingent bank regulation with unobserved actions and unobserved characteristics".

0408 Ana Fernandes: "Knowledge, technology adoption and financial innovation".

0409 Enrique Sentana, Giorgio Calzolari and Gabriele Fiorentini: "Indirect estimation of conditionally heteroskedastic factor models".

0410 Francisco Peñaranda and Enrique Sentana: "Spanning tests in return and stochastic discount factor mean-variance frontiers: A unifying approach".

0411 F. Javier Mencía and Enrique Sentana: "Estimation and testing of dynamic models with generalised hyperbolic innovations".

0412 Edward Simpson Prescott: "Auditing and bank capital regulation". 
0413 Víctor Aguirregabiria and Pedro Mira: "Sequential estimation of dynamic discrete games".

0414 Kai-Uwe Kühn and Matilde Machado: "Bilateral market power and vertical integration in the Spanish electricity spot market".

0415 Guillermo Caruana, Liran Einav and Daniel Quint: "Multilateral bargaining with concession costs".

0416 David S. Evans and A. Jorge Padilla: "Excessive prices: Using economics to define administrable legal rules".

0417 David S. Evans and A. Jorge Padilla: "Designing antitrust rules for assessing unilateral practices: A neo-Chicago approach".

0418 Rafael Repullo: "Policies for banking crises: A theoretical framework".

0419 Francisco Peñaranda: "Are vector autoregressions and accurate model for dynamic asset allocation?"

0420 Ángel León and Diego Piñeiro: "Valuation of a biotech company: A real options approach".

0421 Javier Alvarez and Manuel Arellano: "Robust likelihood estimation of dynamic panel data models".

0422 Abel Elizalde and Rafael Repullo: "Economic and regulatory capital. What is the difference?".

0501 Claudio Michelacci and Vincenzo Quadrini: "Borrowing from employees: Wage dynamics with financial constraints". 